\title{
América Latina y las Antillas Neerlandesas
}

\begin{abstract}
ARNOLD E.' VAN NIEKERK, es investigador del Instituto Interuniversitario de Estudios y Documentación Latinoamericanos de Holanda. Es autor de Sociologie en Sociale Verandering in Latijns Amerika y Populism and Political Development in Latin America, de próxima aparición. Es colaborador frecuente de Estudios Internacionales.
\end{abstract}

Desde hace algunos años las potencias europeas están tratando de liquidar silenciosa - por no decir sigilosamente- los últimos restos, ya casi simbólicos de su pasado colonial en el área latinoamericana. Aunque pareciera que este proceso de desmantelamiento no tiene por lo visto las cruentas características que han acompañado la independencia de muchas otras naciones de otras partes del Tercer Mundo, no quiere esto decir que el futuro de los pueblos de habla inglesa, francesa y holandesa en el Caribe no merezcan serias consideraciones no sólo por parte de los directamente interesados, sino también por parte de las circundantes repúblicas latinoamericanas, las cuales -queriéndolo o no- han visto o verán ampliada su familia regional con algunos nuevos miembros.

Una amplia reflexión en esta materia se impone si nos damos cuenta que detrás del telón poco revelador de las gestiones diplomáticas, está teniendo lugar un espectáculo tragicómico que parece contrariar las enseñanzas de la historia contemporánea. En efecto, al plantear el caso de las Antillas Neerlandesas como ejemplo, nos encontramos con la paradoja de que la potencia colonial representada por el Gobierno de los Países Bajos, está dispuesto y hasta claramente decidido a descolonizar la colonia y que en cambio la colonia no quiere ser libre.

En lo que sigue ya tendremos oportunidad de introducir los matices para apreciar esta paradoja en el contexto que la genera, pero por de pronto conviene esta formulación del problema para reflejar la esencia de la situación existente y para llevarnos a una cuestión que con toda seguridad se seguirá planteando en los próximos años para varios otros territorios en el Caribe. ¿Qué se puede hacer desde 
el punto de vista práxeológico ${ }^{1}$ con la bien intencionada tesis de la autodeterminación de los pueblos en el caso de aquellos países donde por una razón u otra no están dadas las condiciones, ni está dado el interés en autodeterminarse? En la medida que este problema tiene objetivamente una respuesta, ella tendrá que ser el resultado de un detallado análisis no sólo de las actitudes como tales sino también de los factores contextuales que las han generado.

Desde 1954 las relaciones entre Holanda y sus territorios en el Caribe se rigen por el así llamado Koninkrijkstatuut en cuyo preámbulo se establece que "Holanda, Surinam y las Antillas Neerlandesas dejan constancia de su libre roluntad de adoptar un nuevo ordenamiento jurídico a través del Reino Unido de los Países Bajos, en el marco del cual los participantes podrán atender los intereses propios de cada uno en forma autónoma, promoviéndose los intereses comunes por la asistencia mutua en pie de igualdad".

En el modus operandi de este estatuto se ha establecido la práctica que las Antillas Neerlandesas y Surinam han podido gozar de un alto grado de autonomía en el manejo de su gobierno local, que sólo deja a cargo de Holanda las carteras de defensa y de relaciones exteriores. Aunque los territorios de ultramar están provistos de un gobernador residente, su función se reduce a la representación de la corona que, como en la propia Holanda carece prácticamente de poder efectivo. No deja de sorprender el que hasta hace poco el estatuto haya podido funcionar razonablemente bien, toda vez que su propia concepción contiene unos cuantos elementos que, si no son contradictorios entre sí, de todas maneras tienen un carácter altamente ficticio, especialmente en lo referente a la cláusula poco realista de la igualdad. ${ }^{2}$

En todo caso el motivo principal para promover una reconsideración de dicho Estatuto se originó en los violentos disturbios registrados en Guraçao el 30 de mayo de 1969, cuando el gobierno de.Holanda -cumpliendo obligaciones impuestas por la vigencia del Es-

INos referimos naturalmente al enfoque adoptado por Raymond Aron en Ia cuarta parte de su obra Paix et Guerre entre les nations, París, 1962.

2Obviamente no ha habido ni pudo haber una participación equitativa entre un pais ya altamente industrializado y unos territorios que en términos de desarrollo económico no están muy alejados de la media latinoamericana. Por consiguiente la asistencia mutua se ha reducido de hecho a una afluencia unilateral de los recursos fiscales y de otro tipo procedentes de Holanda. Aun hoy día estos recursos representan una fuente importante si no la principal, de mantenimiento de los gobiernos locales. Esta desigualdad queda consignada por el hecho de que en el Consejo Ministerial del Reino, sólo participan dos ministros plenipotenciarios, uno de las Antillas y otro de Surinam, al lado del gabinete en pleno de Holanda, que en caso de desacuerdos siempre tiene asegurada la abrumadora mayoría. 
tatuto- se vio en la necesidad de despachàr un contingente militar300 hombres en total- para ayudar a las autoridades locales a restablecer el orden público.

Aunque en las causas, muy dispares, y hasta ahora poco esclarecidas de esta revuelta, el motivo de una resistencia anti-colonialista no parece haber jugado un papel muy importante, el hecho como tal contribuyó grandemente a que la opinión pública holandesa, hasta ahora poco consciente de sus relaciones de ultramar, se sensibilizara ante las responsabilidades involucradas en tales relaciones. Los círculos políticos comenzaron a preocuparse más directamente por el llamado Artículo 43 del Estatuto que constituye un corolario muy palpable de la idea de la asistencia mutua. Según este artículo-que fue invocado por las autoridades de Curaçao en 1969- el gobierno de Holanda estaría de facto en la obligación de mezclarse en los asuntos internos de uno de los miembros del Reino para reprimir una manifestación popular. Si bien el Estatuto tiene previsto este tipo de situaciones excepcionales como una responsabilidad colectiva de todos los miembros del Reino, de hecho sólo Holanda está en capacidad de llevar a cabo semejante acción. La falacia de la "asistencia mutua" -y su contradicción con otras pautas del estatutosalta a la vista si nos damos cuenta de lo impensable que sería una iniciativa semejante emprendida por uno de los gobiernos de ultramar para acudir en auxilio del orden público en Holanda.

La reticencia a verse comprometido con los posibles desaciertos locales de un gobierno impopular y el temor de que tal compromiso pudiera ser interpretado por la opinión pública internacional como una gestión colonialista, impulsaron por parte de Holanda las actuales negociaciones sobre el futuro del Reino ya que en el estatuto actual la conjugación de los principios de igualdad, autogobierno y asistencia mutua llevan a situaciones ambiguas y contradictorias.

Aleccionados por la traumática experiencia de una sangrienta guerra colonial en contra de la liberación de "su" Indonesia -liberada al fin- los holandeses habían venido asumiendo frente a las Antillas y Surinam una actitud más prudente en la expectativa de dejar cualquier proposición tendiente a cambiar su actual status a ellas mismas. Desde hace algunos años sin embargo el gobierno holandés ha recalcado en reiteradas oportunidades su perfecto derecho a tomar iniciativas en este sentido. Estos planteamientos han producido tanto en las Antillas como en Surinam un cierto efecto de consternación agravado por el hecho de que desde hace algunos meses el gobierno holandés está en manos de una coalición de centro-izquierda, sustentada en el partido laborista que se sabe partidario de una más rápida liquidación de los últimos reductos coloniales en lo que los holandeses suelen denominar como De West (El occidente). Siempre 
en el supuesto de que Holanda seguirá suministrando un apreciable cantidad de ayuda financiera, se ha llegado por parte de Holanda a proponer ya tentativamente una fecha concreta - 1975- para la formalización de la completa independencia.

Las fuerzas políticas de la metrópoli quedaron un tanto sorprendidas por las reacciones más bien negativas de ultramar ante unos planteamientos que se creían imbuidos en el mejor espíritu progresista en pro de la autodeterminación de los pueblos. Cundió la sospecha de que después del equivocado aferramiento colonialista en las antiguas Indias Orientales, se pudiera caer en el otro error de precipitarse demasiado en las Indias Occidentales, empujando a éstas a una independencia que aparentemente no era ni es deseada por las propias colonias.

$\mathrm{Si}$ bien las razones que fundamentan la reticencia de Surinam y las Antillas no son exactamente idénticas, todas ellas se reducen en última instancia al criterio de que algunas de las condiciones mínimas para convertirse en naciones viables, no están dadas.

En Surinam se trata más bien de actualizar primero algunas potencialidades que tiene el país para su futuro desarrollo económico y social. Hasta ahora la economía del país depende altamente de la explotación de la bauxita que suministra el $30 \%$ del PNB y el $90 \%$ del valor de sus exportaciones, reduciéndose el empleo disponible en este rubro a un $7 \%$ de la población activa. Hay además una exportación de cierta importancia en productos madereros. En los planes de industrialización, casi totalmente financiados por Holanda, se ha logrado un cierto progreso en materia de infraestructura pero el reducido tamaño del mercado deméstico y el alto grado de desempleo siguen siendo una importante limitación para cualquier esfuerzo de envergadura en este sentido. Aproximadamente el $70 \%$ de la población está concentrado en los alrededores de la capital Paramaribo. La estructura poblacional del país puede compararse en cierto sentido con la vecina Guyana -anteriormente Guyana Británica- con un $31 \%$ de población negra, $37 \%$ de hindúes y un I5 \% de javaneses, dividiéndose el $17 \%$ restante entre chinos, blan$\cos$ y otros.

Ia mayoría de los partidos políticos no son movimientos ideológicos, sino que se sustentan en afiliaciones étnicas. La única excepción se refiere al Partido Nacional Republicano, el único que se ha declarado inequívocamente a favor de una inmediata independencia. Sin embargo, en recientes elecciones este partido dirigido por Eddy Bruma - considerado por algunos como el Cheddy Jagan de Surinam- obturo una votación muy reducida. Los dos partidos que se disputan la mayoría son el Partido Nacional de Surinam y 
el Partido Unido Hindustani. La rivalidad entre ambos proviene mayormente del antagonismo étnico entre la población negra que adhiere al primero y los hindúes que se agrupan en el segundo, y del hecho de que los hindúes en razón de su más fuerte crecimiento demográfico, pudieran aumentar en el futuro su peso político. Este factor ya se ha registrado últimamente cuando el gobierno de mayoría hindustani se ha venido mostrando un ferviente partidario de postergar la discusión sobre la cuestión de la independencia.

Respecto a las Antillas - geográficamente cercanas pero culturalmente muy distintas y jurídicamente separadas de Surinam- las perspecticas económicas no son tampoco muy halagüeñas. Desde las primeras décadas del siglo el debilitamiento de su tradicional función de enlace en el comercio internacional quedó compensado por el establecimiento de dos compañías petroleras dedicadas al procesamiento del petróleo, mayormente procedente de Venezuela. Con el apoyo de algunas actividades anexas, la industria petrolera. logró dar un cierto auge a la economía de las islas -siempre con mayores beneficios para Curaçao que para las otras- pero desde que las compañías pasaron a la modernización de sus ya anticuadas instalaciones, su capacidad para absorber mano de obra se ha reducido bruscamente, contribuyendo así a la muy elevada tasa de desempleo que se ha registrado en el último decenio. Como en Surinam los movimientos migratorios a Folanda, facilitados por el libre tránsito de ciudadanos en todos Ios territorios del Reino Unido, ha representado una especie de salida escapatoria al problema del desempleo. Otra parte del problema ha sido obviada por la rápida expansión de la industria turística pero ya hoy surge la impresión de que esta actividad está llegando a su límite a no ser que se implemente un vasto plan de inversiones en infraestructura y servicios conexos para dar un mayor aliento a este rubro. Mucho se ha especulado sobre la posibilidad de atraer industrias interesadas en acogerse al régimen preferencial otorgado a Ias Antillas en su calidad de miembro asociado de la Comunidad Económica Europea pero lo cierto es que poco o nada se ha logrado en este sentido. Asimismo la vieja idea de facilitar la localización de empresas orientadas al mercado latinoamericano parece poco realista en vista de las actuales tendencias de la industrialización regional.

Desde el punto étnico, las Antillas presentan una estructura que parece ser menos complicada que la de Surinam. Sĩ descontamos la diferencia ya no tan aguda entre el elemento originariamente indio de Aruba y el mayor peso del elemento negro en Curaçao, nos quedamos con el hecho obvio de una estratificación donde el prestigio social, la posición económica y el nivel educacional van correlacio- 
nados con el color de la piel, en el sentido de ofrecer mayores oportunidades a medida que las características físicas se acerquen más al modelo normativo de los blancos, llamadas "macamba"3: Si bien este antagonismo latente se refleja hasta cierto grado en la afiliación política, los partidos mayores no difieren mucho entre sí, tratándose de organizaciones poco estructuradas, sustentadas más bien en el liderazgo personalista y una variedad de mécanismos clientelistas. En la medida que -en medio de un comportamiento político típicamente pueblerino- el elemento ideológico juega algún papel, se podría hacer una distinción entre por una parte el Partido Democrático (y su gemelo en Aruba, el PPA) que tiene algún parentesco con el movimiento social-demócrata, $y$, por otra parte el Partido Nacional Unido que se considera orientado hacia la democracia cristiana y que incluso tiene algunos vínculos con esta coiriente a nivel latinoamericano. Como consecuencia del movimiento insurreccional de 1969, se ha formado un Frente Obrero que sigue siendo muy inorgáaico aún y cuyo aparente parentesco con ideas revolucionarias al estilo cubano no pasan de un marco más bien folklórico.

EI problema que incide más directamente en la cuestión de la independencia, tiene que ver con la fragmentación geográfica que resulta en gran parte de la situación insular y que se refleja en las permanentes dificultades para establecer un gobierno que pueda ejercer una autoridad suficientemente sólida y reconocida como tal por los diversos territorios insulares.

Las Antillas tienen actualmente una estructura federal que permite a cada una de las islas un alto grado de autonomía interna. A nivel de la representación política y de muchos servicios gubernamentales, sin embargo, el papel de Guraçao - que junto con Aruba contiene el $90 \%$ de la población total (215.000 habitantes) - es claramente dominante, lo cual se resiente en las otras islas que necesitan de la autorización del gobierno central en Willemstad, aun para sus decisiones puramente administrativas. Asimismo los escaños del Congreso con sede en Willemstad favorecen permanentemente la mayoría de Curaçao. Sobre un total de 22 escaños, 12 corresponden a Curaçao, 8 a Aruba, 1 a Bonaire y 1 a las tres islas de Barlovento (St. Eustatius, Saba y St. Maarten).

Estos últimos territorios que se encuentran a una distancia de 1.000 kilómetros de la capital, constituyen de hecho un mundo aparte, donde hasta el idioma es distinto al Papiamento que se habla en el resto del territorio.

Pero aun dentro del mismo ámbito de Sotavento existen ciertos

"Para un penetrante estudio en esta materia véase Harry Hoetink, Het Patroon van de oude Guraçaosche samenleving (english summary), Aruba, 1966. 
antagonismos, especialmente entre las dos islas mayores Curaçao y Aruba, siendo así que en esta última acaba de formarse un nuevo movimiento político (Movimiento Electoral del Pueblo) en base a la reclamación de un llamado "status aparte", reflejando la aspiración de independizarse o hasta de ser incorporada como provincia de Holanda -aspiración fuertemente resisticla por el gobierno ho landés - a fin de deshacerse de la dominación de Curaçao.

Para salir de una situación que, al margen de un status formal de autogobiemo, sigue siendo de tipo colonial desde el punto de vista sociocultural, ¿cuáles son en estas condiciones poco envidiables, las perspectivas del futuro?

Aunque no se ha podido llegar por de pronto a ninguna formulación concreta -entre otras cosas porque nadie está dispuesto a llevar el gato al agua- teóricamente es posible pensar en varias alternativas:

1. La tesis de la completa independencia. Aunque la ciencia política está aún lejos de poder epecificar las condiciones mínimas para el funcionamiento de un Estado-nación ${ }^{4}$, el caso de las Antillas Neerlandesas parece asemejarse a lo que Jaguaribe llamara una vez las naciones no-viables de América Latina. Aun si dejáramos de lado los factores de la situación de base que acabamos de sintetizar y que aun justifican el calificativo de "islas inútiles" que les dieron los españoles, se supone que esta alternativa ha de estar sustentada en algún elemento volitivo, compartido si no por las grandes mayorias - porque ya sabemos que no son las grandes mayorías las que cambian el rumbo de una sociedad- por lo menos por alguna minoría creadora. Al revisar la experiencia de descolonización de los últimos 25 años no es difícil detectar el papel conductor que ha tenido algún estrato dirigente, sea a nivel de la élite militar, política, burocrática, religiosa o intelectual, sea a nivel de una clase socio-económica en la consecución de la independencia y de la afirmación nacional. En las Antillas no existe realmente una clase dirigente con vocación y capacidad de poder. Con referencia a la situación racial, lo que existe a lo sumo es, en los términos de Aron, una categoría dirigente que sin embargo, en vista de su débil estructuración y su esquizofrenia cultural, sería incapaz para siquiera intentar una salida a la Rodesia.

Los grupos dirigentes reciben por otra parte muy pocos estímulos o presiones desde abajo, ya que a nivel de los estratos populares,

'La tesis expuesta por Lucian Pye en su Aspects of Political Development, Toronto, 1966, es muy estimulante en este sentido, pero no se refiere directamente a la cuestión de las condiciones mínimas. 
los valores inculcados a través de las generaciones, especialmente a través del sistema educacional, nunca han puesto en tela de juicio la bondad de las pautas importadas desde la metrópoli. El apego a estas pautas es a veces sorprendente si nos damos cuenta de que algunas de ellas están de hecho muy reñidas con la realidad local donde se producen toda clase de situaciones incongruentes. ${ }^{5}$

En esta perspectiva es comprensible, pues, que las Antillas tienen poco interés en seguir el ejemplo de otros países recién liberados que, aparte de su reconocimiento internacional, no cuentan con los resortes de poder indispensables para por una parte contener las múltiples fuerzas centrífugas internas y por la otra resistir la gravitación de otras potencias cercanas. Y'a existen varios ejemplos que demuestran que este tipo de "naciones de opereta" puede convertirse en un teatro de verdaderas tragedias humanas con su secuela de guerras intestinas, de intervenciones ajenas, o aun de las garras del gangsterismo internacional. De todas maneras, si de acuerdo a la situación actual, el gobierno pro-independientista de Holanda se conforma con la actitud de respetar la voluntad mayoritaria de su colonia, lo más probable es que la situación seguirá tal como está.

${ }^{5}$ Se da el caso de que la reforma educacional que se inició en Holanda bajo la llamada Ley Mamut para diversificar y adaptar el curriculum de la enseñanza media a los requisitos de un país altamente industrializado, fue copiada sin más en las Antillas Neerlandesas. Desde antes ya la concepción general ha sido tal que la. enseñanza primaria y secundaria se encuentran en función directa de la enseñanza superior en el sentido de que las primeras sólo tienen sentido como trampolín para aquella parte muy minoritaria del alumnado que continúa sus estudios hasta el nivel de la educación superior, cuyo acceso está reservado a aquellos que puedan trasladarse a Holanda porque las propias Antillas no cuentan con tales establecimientos. Así, la gran mayoría de los bachilleres se encuentra de hecho con las manos vacías, no sólo porque no pueden continuar sus estudios superiores, sino por el hecho de que los conocimientos adquiridos en el colegio no sirven mucho para "ganarse la vida", y sólo tienen sentido si se puede llegar efectivamente a las universidades holandesas.

De hecho la situación es tal que demasiados jóvenes antillanos se han venido formando demasiado bien como para encontrar empleo en una economía que no tiene la capacidad expansiva para absorberlos. Es simbólico el hecho de que en semejante situación se ha debido recurrir a programas especiales de reorientación vocacional para atender los desempleados egresados de la enseñanza secundaria a fin de hacerlos volver a un nivel más "bajo" en el ramo de las profesiones técnicas y administrativas.

Asimismo la adiministración pública se presenta como una réplica del sistema holandés y parece poco apto para que las instituciones del Estado puedan hacerse cargo de la multitud de iniciativas que, como en América Latina, hace falta acometer en materia de desarrollo económico. De la misma manera en el campo de la legislación obrera, de seguros sociales y de salud pública se ha adoptado un generoso sistema de prestaciones que no es el resultado de las reivindicaciones populares y que guarda escasa correlación con el nivel de desarrollo económico, constituyendo asi una carga bastante pesada para una base productiva muy estrecha. 
2. La tesis de la Mancomunidad. En aras de una solución de compromiso algunos han pensado en la posibilidad de seguir el ejemplo británico de una especie de mancomunidad que, sin implicar las obligaciones de un sistema federativo o confederativo, mantendría un cierto margen para atender determinados intereses comunes, especialmente a nivel económico y cultural. Cuando esta idea surgió por primera vez hace algunos años, el gobierno holandés la descartó rápidamente con el argumento de que semejante figura, ya superada en el propio ejemplo británico, no se compagina ya con el carácter de las relaciones internacionales en los tiempos actuales. Además si la mancomunidad británica ha tenido su significado, este se debe en gran parte al poder económico de sus miembros, reunidos en la común defensa del llamado bloque de la libra esterlina, factor éste que está totalmente ausente en el supuesto de una mancomunidad holandesa.

3. La tesis de la asociación con otras ex-colonias en el Caribe. A primera vista esta es la solución que se presenta como la más lógica, toda vez que muchos de los problemas de las Antillas son lo mismo que en Martinique, la Guyana Francesa, la antigua Guyana Británica, Jamaica, Trinidad y Tobago, Barbados y otros territorios que en una $u$ otra forma han venido compartiendo la experiencia de una relación colonial con los países europeos. La realidad local presenta sin embargo obstáculos que, si bien pueden parecer de poca monta a un observador de afuera, adquieren a nivel local una considerable importancia: las dificultades en las relaciones entre los pueblos no aumentan o disminuyen en razón de su tamaño sino en razón de su manera de ser. Basta recordar el muy fugaz establecimiento en 1958 de la Federación del Caribe Británico que sólo tardó 4 años en desmembrarse cuando Jamaica y Trinidad, contrariando concepciones jurídicas muy bien intencionadas, se salieron de la federación por razones de política local, fuertemente alimentada por el carácter insular de sus territorios -muy alejados entre sí y muy desiguales en la disposición de sus recursos.

Podría decirse que tanto en el Caribe Británico como en el Caribe Holandés el problema se reduce en última instancia a lo que se llama una divergencia cognitiva: las islas menores abrigan el temor de ser explotadas para ventaja de las islas más grandes. Estas últimas, sin embargo, consideran su asociación con las islas pequeñas y menos desarrolladas, no como una ventaja sino como un lastre y una carga inconveniente. Si esta ha sido la experiencia dentro de un solo ámbito de influencia solonial, una gran asociación entre territo 
rios con antecedentes coloniales diferentes aparece más bien como una posibilidad muy remota.

4. La tesis del Estado asociado con Venezuela. Para una consideración de esta alternativa - fuertemente apoyada en pesados factores geo-políticos- hay que partir del hecho de que la realidad social moldeada en muchos de sus aspectos por la influencia de la metrópoli, ha producido frente a América Latina un alejamiento cultural que supera con mucho la corta distancia que existe en términos de comunicación física. Especialmente por lo que respecta a su convulsionada praxis política y sus corrientes ideológicas, el mundo latinoamericano se percibe como esencialmente ajeno. En gran parte como consecuencia de la pura ignorancia y del apego a las comodidades del colonialismo -que también las hay- un acercamiento hacia América Latina se siente como una especie de degradación.

Por parte de Venezuela siempre ha existido un interés especial por las Antillas toda vez que éstas en más de una oportunidad han servido como un refugio para una gran variedad de exiliados venezolanos y una base de operaciones subversivas para muchas intentonas históricas para tumbar el gobierno de turno en Venezuela. Ultimamente se añaden a esta circunstancia histórica ciertos indicios de que la fuerte expansión económica que ha tenido Venezuela en el último decenio está empujando a ciertos factores productivos - particularmente el factor capital- hacia afuera en búsqueda de nuevas oportunidades de inversión.

Esta tendencia se apoya por lo demás en el hecho de que el gobierno venezolano está llevando, desde hace algunos años una original política exterior de clara apertura hacia el Caribe, en cuyo marco no sólo el activo Ministro de Relaciones Exteriores sino también el propio presidente de la república, acompañado por su gabinete en pleno, ha realizaclo visitas a las islas vecinas, las cuales -al decir de los venezolanos - sólo un anacronismo histórico ha enajenado de lo que debería ser el patrimonio natural de su país.

Añádase a esto la actualidad de un litigio pendiente sobre la delimitación de áreas marinas entre Venezuela y Aruba, y se comprenderá que las diminutas Antillas comienzan a abrigar ciertos temores frente a un país del continente que efectivamente se está convirtiendo en un gigante económico al par con Brasil y México.

Es significativo el hecho de que: los temores antillanos -comprensibles pero hasta cierto grado artificiales también- no son compartidos en la misma medida por todas las capas sociales. En los pequeños estratos superiores han existido siempre -sobre todo a través de los nexos familiares- numerosos intereses y vínculos económicos con Venezuela, hasta el punto de que en la élite venezolana no es raro 
encontrar prestigiosos nombres de origen antillano y viceversa. Es sobre todo a nivel de las clases populares, en su gran mayoría de formación negra, donde se teme que una asociación con Venezuela pudiera conducir a un empeoramiento de su situación económica y racial que hasta ahora es compensada hasta cierto grado por un bien organizado sistema de protección social derivada de la tutela holandesa.

El temor probablemente no radica en la expectativa de una discriminación racial - problema más bien ajeno a la tradición venezolanasino en la perspectiva de que a partir de una sociedad donde el elemento negro forma mayoría, se pasará a un país de casi 12 millones de habitantes donde les tocará la suerte de una minoría más bien insignificante. Vuelve aquí el problema de la divergencia cognitiva. Para las Antillas una salida de este tipo equivale a una entrega para beneficio de un futuro explotador. Para los venezolanos, muy al contrario, este posible "beneficio" no es tal, en vista de la pesada carga involucrada en esta solución a la puertorriqueña. Independientemente de las aspiraciones territoriales geopolíticas que puedan estar de por medio, los dirigentes venezolanos están bien conscientes de que su país sencillamente no está en condiciones de asumir semejante responsabilidad -piénsase por ejemplo en la dificultad de absorber aparte de su propia tasa de desempleo, la mano de obra antillana ociosa- que aun en el caso de los Estados Unidos no parece ser la que más convenga.

5. La tesis del "estatuto blando". Esta posibilidad parece ser la que se presenta con mayores perspectivas inmediatas. Ella consistiría en adaptar algunas cláusulas del estatuto vigente, convirtiéndolo de hecho en un mecanismo de transición para facilitar y dejar abiertas otras soluciones definitivas que no sean la continuación del statu quo. Descontando que el gobierno holandés - pasando por alto cualquier resistencia antillana- insistirá en una definición hic et nunc del status definitivo -incluyendo una fecha límite para la expiración del actual- Ia más importante modificación que se impone es la de eliminar la cláusula referente a la obligación holandesa de corresponsabilizarse en casos de emergencia, del orden público interno.

Observando el proceso de la clescolonización de la post-guerra en retrospectiva y considerando su secuela actual, se han creado ciertamente muchas situaciones en que el reconocimiento de más de un estado nuevo ha ocurrido a nivel internacional, antes de haberse producido a nivel doméstico. Nuestra conclusión, pues ha de terminar necesariamente en una interrogante. Todo el mundo puede 
ESTUDIOS INTERNACIONALES

estar de acuerdo en que todos los pueblos están en su perfecto derecho para autodeterminarse. Pero ¿también lo están para no hacerlo? O dicho de otro modo: ¿Existe -o puede imponerse- el deber para que los pueblos se autodeterminen? 